\title{
COST, ACCESS, AND QUALITY IN ONLINE NURSING AND ALLIED HEALTH PROFESSIONS
}

\author{
Tracy Wright \\ Department of Practical Nursing \\ Northwest Technical College \\ Address: Northwest Technical College \\ 905 Grant Avenue SE \\ Bemidji, MN 56601-4907 \\ Telephone: 218-755-4270 \\ Email: Tracy.Wright@mail.ntc.mnscu.edu
}

\section{Linda Thompson}

Department of Distance Education

Northwest Technical College

Address: Northwest Technical College

PO Box 309, Perham, MN 56573

Telephone: 218-347-6216

Email: Linda.Thompson@mail.ntc.mnscu.edu

\begin{abstract}
Northwest Technical College researched, planned for, and has successfully implemented a unique delivery of its Practical Nursing Program through the use of Internet technology. This Distance Practical Nursing exploratory paper presents a historical overview of the program, assesses job market needs in the field of nursing, evaluates use of varying delivery methodologies, outlines program successes, and identifies barriers to distance delivery of this health curriculum. The essential components of quality, access, and cost are highlighted and related to the unique challenges they present in the field of distance education.
\end{abstract}

\section{KEYWORDS}

Cost, Access, Quality, Nursing and Allied Health Professions

\section{INTRODUCTION}

The National Education Association (NEA) identifies seven benchmarks of quality measures in distance education including (a) course structure, (b) course development, (c) institutional support, (d) student support, (e) faculty support, (f) teaching/learning, and (g) evaluation/assessment [1]. Cost, access, and quality are highlighted categories that are frequently debated in academe and are on the minds of college administration, college faculty, students, and industry. This article explores one distance program's history, experience, and growing pains in the framework of cost, access and quality through the on-line delivery of a practical nursing program. 
Northwest Technical College (NTC), a dual mode college, provides both onsite and distance delivery of education for employment. The college serves-northwestern Minnesota through a virtual campus and five bricks/mortar campuses geographically separated by significant distances (100+ miles). NTC develops workforce capacity by providing quality occupational learning opportunities and services to meet a variety of career choices and customer needs. NTC serves traditional and distance learners, employed workers and businesses by providing industry-validated technical and general education curricula. Working cooperatively with higher education and business partners, the College graduates capable workers at the occupational entry level and upgrades skills to meet changing industry needs. Program graduates are awarded Certificates, Diplomas, or Associate in Applied Science Degrees.

Although learner characteristics vary by location and preferred educational modality, NTC expects learners to attain the program major's desired performance outcomes regardless of location or educational modality. Thus, the college focuses on continuous improvement of policies, procedures, curriculum, and approaches to education that apply to all students including those learning at a distance. NTC has studied the demographics of its distance population. This research has identified the common distance education learner's profile to be that of an adult, gainfully employed, having family responsibilities, and in the 2535 age group, enrolled in either distance courses exclusively or an on-campus/distance combined curriculum. Utilizing this information, NTC has tailored its approach to student life using language that is relevant to the on-campus, distance, and dual-mode students.

The college's practice of designing like degrees with consistent course requirements and sequencing patterns whether delivered through one of the five traditional campuses or the virtual campus allows students to freely create an individualized program schedule that fits their personal needs for convenience, flexibility and adaptability as it pertains to their life situation or location. Specific to the healthcare field, NTC has created a Distance Practical Nursing Degree Program. Although delivered through distance modalities, the design of the degree and performance levels of students align with the college's other oncampus programs. Financial support from the Sloan Foundation and TRANSCENDS (To Reach All Nursing Students with Cultural Excellence in Nursing Development Skills) gave the college opportunity to develop the practical nursing curriculum into distance modalities. Review of the college's four-year history as a provider of distance courses reveals an evolution that leads to the current situation.

As is the case with most distance delivery modalities, cost continues to precipitate much discussion regarding the practice of distance education at NTC. Development of a high quality program requires a significant pre-delivery investment to address course planning, development, and delivery with special attention granted toward technology and personnel needs. In the original pilot project to develop and deliver a distance version of the practical nursing degree program, the pre-delivery investment and beta delivery was funded in partnership with TRANSCENDS. Procurement of the external funds not only made the project possible but also helped ensure a quality experience for students. Through the pilot, the college learned the highest costs of delivery were associated with the clinical and lab experiences wherein smaller student-faculty ratios were required to ensure proper nursing skills and safe practice. In addition, moving from a history of delivering courses into delivery of an entire program created additional unanticipated expense in non-classroom expenses such as program admission, transfer of credit, tutoring, library and other student support services. It was also noted for purposes of financial stability that a program not supported by external funds would need a greater number of students to break even at the general tuition rate.

\section{STATEMENT OF THE ISSUE}

Blending the essential components of quality, access and cost in distance education creates several unique challenges. As educators, quality is an issue that comes naturally, one for which there are many pedagogical strategies and established instruments to measure and ensure quality. The issue of access 
brings challenges regarding would-be learners' access to required technology including up-to-date computers, required software, the Internet, non-limiting e-mail, and adequate bandwidth connections. In addition to technology access, a successful distance program required access to students who possess the skills to effectively use the technology. Furthermore, the college requires distance education to selectively market to targeted groups, mainly individuals and groups with recognized barriers that prevent their participation at one of the college's on-campus programs. Along with quality and access, considering the cost of delivery is a sizeable issue. Delivery costs need to be clearly outlined so that efficient and effective plans are in place to anticipate these unique and sometimes hidden costs.

Online programs have allowed higher education to serve a market that was previously impossible to reach. Online healthcare programs are beneficial not only to higher education, but are also of great benefit to the many communities void of qualified healthcare workers. While online education has several strengths, it has also created many stimulating and provocative discussions focusing on program review. This paper strives to explore the challenges of cost, access and quality related to distance education.

\section{A. Access: Distance Education Today}

Statistics from the last five years highlight dramatic increases in applications of distance education. According to a 1989 congressional report, fewer than ten states were promoting distance education in 1987 while today almost all 50 states have a vested interest in distance delivery. Distance education exists in most countries of the world, as well. Iowa Public Television reports that the growth in this delivery mode is primarily related to "increases in educational requirements that have coincided with the expanding capabilities and services of the telecommunications industry" [2]. Iowa Public Television also reports that distance education is seen as a viable and cost-effective way to meet the challenges of teacher shortages, low student enrollments, and decreased funding in the traditional modality.

\section{B. Public Expectations}

The general public of today expects that education will be brought to them. Location and time are no longer prerequisites to participation in higher education [3]. Individuals are seeking to increase their education and firms are seeking to have e-education delivered onsite for employee training and skill upgrades [4]. According to Public Agenda's new survey, "in the public's mind a college education has replaced the high school diploma as the gateway to the middle class. The public's focus isn't just on the credential but on the personal growth, skills and perspective that students take away from a college education" [5].

\section{Demand for Nursing}

While a general college education meets consumer expectations, employer demands for individuals with an education specifically in the field of nursing has become a nation-wide crisis. A 1998 Nursing Shortage Study by a health care consultant company, Hay Group, surveyed 178 hospitals throughout the nation. An alarming $81 \%$ of the respondents indicated a current or anticipated shortage of all levels of nursing including practical nurses at their institutions [6]. The Minnesota Nursing Association (MNA) has also confirmed that a nursing shortage is presently straining Minnesota health care facilities [7]. "Within an economy that is experiencing chronic worker shortages, the health care industry is having great difficulty in retaining licensed and unlicensed personnel" [7]. Peter Buerhaus, RN, Ph.D. reports that the shortage will be chronic (as opposed to cyclic) and is attributed to an aging nursing work force, an aging United States population, unsatisfied nurses leaving the workforce, and decreased nursing program enrollments [7]. In addition to looking at retention efforts, the MNA is seeking to bring together nursing educators, staff, and industry to discuss strategies for increasing nursing student prospects. Distance education is the answer to the accessibility issue that plagues student nurses aspiring to climb the career 
ladder and licensed nurses who are interested in educational advancement [8]. According to the American Association of Colleges of Nursing (AACN):

Distance education also helps to counter the nation's mounting nursing shortage by bringing nursing careers to people who wouldn't otherwise follow that path because they lack access to a campus, or because work, family or economic considerations preclude a full-time, on-site education. Moreover, educators point out, distance courses fight 'brain drain' from rural areas: students who learn within their own communities are more likely to practice there, and working nurses taking advanced degrees via technology can continue to serve their patients [8].

\section{NTC's Solution}

The aforementioned data supports NTC's mission of bringing education to individuals who are seeking it. Traditional barriers to education such as distance, financial burdens, and family responsibilities should not be so great that they discourage people from seeking a nursing education. NTC helps bridge the gap by providing convenient online learning that preserves students need to remain in the workforce and be close to family. According to Sally Kuhlenschmidt, director of the Center for Teaching and Learning at Western Kentucky University, "formerly isolated students are gaining technological skills that allow them to stay near families and still meet their need to connect with the world and grow their education. These students' lives are getting easier and richer because of their online connections" [9].

E.D. Hirsch wrote a precautionary statement in regard to the digital divide as it impacts children. This message, while intended for application to children's education, could easily be adapted and applied to all students seeking education who encounter digital and geographical barriers:

To give all children a chance to take advantage of the new technology means not only seeing to it that they have access to the technology but also ensuring that they possess the knowledge necessary for them to make effective use of it. Our responsibility as educators is to define the knowledge our students need and - through a lively variety of pedagogical techniques - to help them master it [10].

NTC strives to offer unique, meaningful, educational, and stimulating courses in a distance format. In order to maximize students' learning of the coursework, NTC offers an introductory on-line computer course the very first semester of the curriculum. This sequencing of courses allows students an entire semester to become computer literate so their time and energy can later be better spent on mastering the content of the nursing coursework rather than fighting the technology. Students gain computer proficiency that is not only an asset to their education, but also an asset to their future careers. Today's highly technical healthcare field utilizes computerized medical equipment and digitized charts. Telehealth and telenursing have become a reality "for the provision of long-distance clinical health care, patient and professional education, and health administration" including home health visits and emergency medical response systems [11]. Distance nursing helps prepare students for a future in nursing.

\section{E. Enrollments}

The revolution of new technology and the growth of distance education have given organizations the opportunity to provide educational access to a population which was once underserved due to work, family, age, disability, geography, and/or economic responsibilities [12]. Many of these learners include people who live remotely or are engaged in full-time employment in all sizes of communities. NTC's distance students enroll in the Practical Nursing Program due to a wide variety of reasons that are similar to those noted on the national level. Students' motivations for seeking out a distance program option range from living in remote location without educational facilities to living in an urban location with employment commitments that restrict access to traditional classroom offerings.

Since the implementation of the Distance Practical Nursing Program in 1997, the two classes of graduates consisted of students from rural North Dakota. Participation increases resulted in a second graduating class of 26 students, more than 100\% larger than the first group of 11 students. Students from Minnesota, North Dakota, Washington, and Massachusetts compose the third class, started in Fall 2000. 
In addition to the aforementioned distance program graduates, several other students took advantage of one or more Distance Practical Nursing courses to complement their program of study at the traditional campuses. These students, from one of the NTC campuses' Practical Nursing Program and other regional colleges, selectively enrolled in specific distance courses due to health, family, scheduling difficulties oncampus, or other underdetermined reasons. While not a targeted group or carefully studied, the very existence of these students in distance courses and popularity of the dual modality options for more traditional students in and of itself is revealing. The phenomena proved that supplemental course access through convenient and flexible distance education is also valuable to graduation tracks for students who are majoring in a traditional on-campus program.

The pilot program allowed NTC to recognize inherent differences in successful curriculum layout for distance students as compared to on-site students. Unlike most students participating in the traditional campus programs, distance students were typically adult learners who continued to live, work, and raise families in home communities. Due to the need for continuing employment while meeting family responsibilities and pursuing their education, this population had a very difficult time moving through the core courses of nursing within the usual four semesters since it required a full-time academic load. As NTC moved from the pilot phase to the implementation phase, program planners recognized that it was important that the curriculum layout be reflective of the educational patterns of distance learners and conducive to success. Therefore, a flexible entry option was created to allow degree completion over an eight-semester period rather than the traditional pathway of four semesters. This new sequencing option along with astute marketing techniques connected approximately 50 students seeking to complete the nursing degree offered through distance education.

Telephone interviews and e-mail exchanges with prospective distance students reinforce the need for a distance option. Through the inquiry process, students who contacted NTC's Distance Education office were asked if commuting to one of the college's five campuses or another regional college was an option for them. An astounding $75 \%$ of the potential students said enrollment into a traditional on-campus program was not a viable option for them. It is important to note that even students, who live in a metropolitan area such as Minneapolis, responded that due to work and family situations, if the opportunity to educate via technology did not exist, they would have been completely left without access to the continued education they were desperately seeking.

\section{LEARNING EFFECTIVENESS/QUALITY: GENERAL DISTANCE EXPERIENCE}

\section{A. Cornerstone concepts of the distance program}

The exponential growth of internet-based distance learning draws attention to quality considerations and interest in online education continues to grow at all levels, locally, nationally and across the world. Undoubtedly, the nature of the learning environment created by the Distance Practical Nursing Program needs exploration. The authors of this paper felt it important to create a shared understanding of the Distance PN Program. The curriculum consists of internet-based theory courses, web-enhanced technical skills courses with accelerated lab components offered at non-traditional times, and mobile clinical courses which occur at different geographical sites dependent upon need. The clinical component, a very important aspect to any nursing program is also important within the distance program. Students and healthcare facilities are reassured that the same amount of student-nurse-patient interaction and hands-on care that would normally occur in a traditional program also occurs in the distance program.

Distance courses are identical to the traditional classroom courses with regard to content, however they vary greatly in delivery. Approaches to assignments, class discussions, testing, and grading are re- 
engineered in order to accommodate on-line learning. These alterations impact not only the student, but also the faculty and institution as a whole. A smooth introduction of courses and programs through the virtual campus and its distance education department was paved through curriculum alignment previously completed by faculty from the five programs at the college's traditional campuses. The on-line program and its courses were aligned with the five campus' desired performance outcomes, curriculum requirements, course content and sequencing. Therefore, students taking a course on one campus whether traditional or virtual, learn through the same basic syllabus and course objectives as all other students.

\section{B. Faculty involvement \& recruitment}

NTC utilizes a best practices model for providing quality on-line courses. Distance PN has been fortunate to draw upon the wealth of knowledge and experience of the college's PN faculty. Nursing faculty throughout the five campuses have willingly contributed their expertise to the on-line PN Program through provision of lecture materials, presentations, assignments, references, activities, clinical simulations, grading methodologies, skill sets, and clinical observation tools. To date, intellectual property rights have not been a central focus of program faculty, rather they have felt honored to have their work enshrined in the college's best practice library. Faculty contributions are evaluated against established best practice standards and assessed to identify duplication, ensure applicability to the course objectives, and emphasize the highest intellectual level of understanding — critical thinking.

The concepts and information gleaned from contributors are designed into an on-line delivery mode with strong consideration granted toward how online learning occurs. It is essential that course material, directions, approaches, and activities be customized for distance. The on-campus material cannot simply be plugged into the Internet. "Courses transported to a distance learning environment without reconfiguration will not survive a student-driven consumer market. To succeed, we need to rethink our teaching" [3]. Next, the information is "mapped" out on a master course calendar. The mapping process allows for all documents to be appropriately labeled and linked preventing student confusion and virtual disorientation within the web page. In addition to content and structure of the on-line courses, there are many other ingredients that are essential to the creation of a successful distance program.

NTC expects distance courses to meet or exceed on-campus quality so it pays attention to the factors supporting quality. Faculty selection is central to establishing a quality learning experience for students. NTC recruits distance instructors from its own established faculty focusing on those who want to be a part of distance and have taught at least one-year on-campus. These criteria ensure that distance instructors have interest, experience, and qualifications that mirror traditional classroom faculty. NTC's expectations are in line with the National Education Association's (NEA) guidelines for assuring quality in distance education [12]. Teachers who are enthusiastic about trying new approaches and are rejuvenated by thinking "outside the box" are ideal candidates for the distance program. Many of the instructors feel a sense of freedom from traditional constraints and are able to institute "lively teaching techniques that motivate students and enhance their active participation in learning" [10]. Teachers become facilitators of communication, learning, and critical thinking by capitalizing on alternate instructional approaches via sophisticated technology.

\section{Student-Teacher Interaction and Resources}

Within NTC's distance program, students play an active role in their education, they become involved. Just as classroom interaction is an integral component of an on-campus course, so must it be within a virtual classroom. Faculty embed interaction in the virtual learning environment through several class participation strategies. Each on-line course has a direct link to the instructor's e-mail and to the course's chat room. The chat room truly promotes a classroom environment. The chat room is used in a combination of asynchronous and synchronous modalities. In some instances, the chat room is utilized as 
a bulletin board for posting course-related announcements and for answering students' questions. The expectation is that instructors respond within a maximum of 72 hours. Instructors make great efforts to be very timely in their responses. In other cases, the chat room is used to post an instructor's generalized input as a follow-up to recent assignments or tests. The Instructional Management Software package, IntraKal, allows the instructor to statistically analyze the class performance on tests. The chat room then becomes an important tool for instructors and students to have a reflective conversation to discuss and clarify the subject matter. Furthermore, instructors also may schedule optional times for synchronous office hours or class study sessions utilizing the chat room. These study sessions provide students and the instructor the opportunity to describe concepts, to analyze level of understanding, to solicit demonstration of knowledge application, and to promote critical thinking. This use of the chat room strives to imitate the types of on-campus activity that would normally occur in the traditional classroom. The experience validates whether students are gaining and have command of scientific learning versus a superficial learning process. It also creates an inviting course milieu and encourages positive studentinstructor relationships. However, these synchronous conversations create a unique dilemma. Participation in the synchronous activities has been limited when they are offered as an optional rather than required activity. On the other hand, when instructors require the activity some students become frustrated. This is not a unique phenomenon to NTC. Adjunct professors of Telecommunications at Stevens, Mohammad Fatehi and M Hosein Fallah say, "The students apparently value flexibility in their schedules and dislike that the chats occur at fixed times" [13]. Overall, chatrooms have promoted conversation between students and faculty. According to Cheryl Rhoads, Assistant Professor of Nursing at the University of Arkansas, online nursing students finished with better grades and conversed more than her on-campus students [14].

Distance instructors also have the important role of referring students to up-to-date resources and journals. Gone are the days when each course had a single textbook resource. Students in the Distance PN program order their books and supplies on-line. They are given the web address to the course. Within the course's calendar (map), the students are referred to several direct-link websites that will provide the student with additional viewpoints and up-to-date knowledge on the subject areas. This is very important, especially considering the pace at which the healthcare field changes.

\section{Grading and testing}

NTC's distance courses also utilize an online grade book and testing software. Discovered during the pilot implementation phase was the importance of student progress being reported in a timely manner. Improvements in software now allow students access to the instructor's online grade book thereby giving the student a concrete understanding of the grading criteria, components of the course grade, individual assignment/test scores, along with an up-to-date cumulative average in the course. The testing software requires students to take their tests in a proctored situation over the Internet. Proctoring policies have been established to accommodate the on-line delivery of the tests and also help insure academic integrity and honesty. The test is immediately graded and the score is automatically placed in the grade book. Students are also e-mailed a list of incorrectly answered questions, the answer they chose, the correct answer, and reference regarding where the information can again be viewed. This immediate feedback encourages students to learn from their mistakes and to correct altered thought processes early on in the course.

\section{E. Student accountability}

Student accountability for work is another important component of on-line delivery. NTC's software allows the instructor to track student access of course material, track student review of grades, chat room contributions, etc. This objective information is important to an instructor when evaluating student progress and grading on class participation. Furthermore, the use of the on-line gradebook, IntraKal testing service, and chat rooms for provision of student feedback and promotion of student/faculty interaction is on target with the NEA's benchmarks for ensuring quality in distance education [12]. 


\section{F. Tutorial services}

On-campus students have access to a learning center that provides tutorial help. NTC felt strongly that this service should be available to ALL students. Tutorial chat rooms are available to the students through direct course links. Tutors for nursing courses are available in both synchronous and asynchronous formats to allow for flexibility and multiple learning styles. Distance students also have a unique and demanding need for technical support. This service is also provided on-line through a direct course link.

\section{SPECIFIC INSTITUTIONAL AND FACULTY GROWTH RELATED TO ONLINE COURSES}

\section{A. Creating one cohesive Practical Nursing program}

Distance Practical Nursing has highlighted the need for similarity between campuses on ALL issues - not just curriculum and course content. Students now freely weave between on-campus and distance courses in their hybrid programs. The dialog that has taken place has been student driven and has been well received by all campuses. Distance PN has given the program the opportunity to truly highlight areas of strength and opportunity. This approach has been instrumental in bringing all the campuses together on several issues such as having similar books, grading methods, approaches to advisement, policies and procedures. This continual march toward sameness has created an opportunity for NTC to recognize differences that had been otherwise unnoticed. The correction of these differences has helped place NTC in an excellent position as it seeks National League of Nursing accreditation. This accreditation will involve a review of all NTC Practical Nursing Programs including distance and requires that all campuses prove quality programming and similarity.

\section{B. Benefits to on-campus instruction}

Distance PN has not only helped to bring the Practical Nursing Programs together as truly one program, but it has also helped on-campus instruction. The relationship between distance and on-campus is symbiotic. Best teaching practices and materials have been gathered, formatted, organized and published to the web. On-campus instructors have free access to this material. Critiquing of the web-material is welcomed and needed for continual quality improvement. The material is kept up-to-date with suggested improvements from faculty and with industry changes. This warehousing of material can truly benefit the on-campus faculty and students. Reinvention of the wheel is not necessary every time a new faculty joins the college or a "new prep" is required. Time can be better spent researching new technologies and new healthcare breakthroughs that can be passed on to the student body and added to the warehoused knowledge base.

\section{Other indicators of quality}

NTC views the delivery of on-line programming as a challenge that is not measured by success and failures, but by analysis of the student achievement. This analysis results in continual improvement of delivery along a continuum of institutional learning. Our quality programming can be objectively measured by our approval by the Minnesota and North Dakota Boards of Nursing. They recognized that the curriculum quality is equal or greater than the on-campus delivery. The only differentiator between programs is the mode of delivery. A second measurement of quality is the 91\% NCLEX-PN pass rate of graduates. Another measurement of success is NTC's ever-changing delivery approaches. The Distance PN program is not static. Faculty have moved the program from disk delivery to internet delivery, asynchronous e-mail interaction to synchronous chat room interaction, the use of limited nursing supplies to supplies being sent to student's homes with the availability of centrally located mannequins. A final measure of quality is the positive impact it has had upon our on-campus faculty. Faculty instruction of on-line courses has increased technological knowledge, sparked enthusiasm, and has gotten all faculty involved in a shared vision. Multiple faculty exposure to the on-line coursework results in a fresh analysis and critical review of the content. The continual evaluation of material is essential to success. Furthermore, on-line students are invited to provide anonymous feedback regarding their experience. 
This collected information is then utilized to validate successes and initiate evolvement towards success in other areas. The authors of this article whole-heartedly embrace the Institute for Higher Education Policy's mission "to foster access to and quality in postsecondary education to promote innovative solutions for the important and complex issues facing higher education" [15].

\section{AREAS OF OPPORTUNITY}

NTC has identified areas that are in need of improvement. These include a seamless process for distance student services, more training for on-line teachers, availability of mentors who are experts at distance delivery, and the need for contractual language to address a standardized and equitable compensation for distance faculty who prepare and instruct on-line courses. According to Thomas Cyrs, professor emeritus at New Mexico State University, "The Achilles' heel of distance learning today is the lack of training, planning time and support for instructors" [3]. Each of these areas of opportunity will directly impact quality level of distance courses.

\section{A. Course development}

Course development for distance delivery is a phase involving time, energy, financing, manpower, technology, and experimentation. "Interviews with faculty show that preparing a quality course for delivery at a distance takes four to five times longer than does a traditional course" [3]. In distance education, it is imperative that the entire course is ready for web posting prior to the first day of class. Faculty need to be hired well in advance to and have the opportunity to begin working on the course material approximately six months in advance. If this planning and development do not occur there is risk of producing a low quality content with minimal student achievement. College administration recognize to simply transfer an on-site course into a distance delivery model without consideration of pedagogical approaches will result in frustrated faculty and poorly served students. Therefore, NTC aggressively pursues external funding to support the time intensive course development processes.

Even with time funded, it is unrealistic to expect faculty members to do it all. Without careful planning, time, and compensation instructors will not be proud of the material despite hours of labor, will become burned out, and will not want to participate in the new technology. This will lead to dissatisfied employees and students. According to Cyrs, "when many different institutions offer similar courses on the same subject only the best will survive. Support services should include the services of an instructional designer, computing and television technical services, training in hardware and software use, graphic design, editing and typing, and help from field site coordinators" [3].

\section{B. Costs of On-Line Course development}

Creation of courses in an online environment requires a blending of course content expertise and technology expertise. To allow faculty to focus on what they do best, NTC has adopted a systems approach to online development. A faculty member is paid an average of 200 hours for his/her contributions to the content development. The faculty member is also paired-up with an instructional designer who facilitates the shifting of content into an online format. The instructional designer is allocated 50 hours of time to assist the faculty member. These hours are filled with designing a site and teaching the faculty how to use the technology product. With this system, the costs of course development remain fairly static. Economies of scale can exist once faculty experienced in distance education pedagogy begin using their experience to create subsequent courses. Once the learner curve is conquered, faculty establish a pedagogical strategy and begin to understand how online activities will occur in their discipline for maximum learning. It is also reasonable that faculty create templates in which they can insert their specific academic content. Furthermore, development costs are kept relatively low and most importantly ensure quality by keeping team members focused on their area of expertise. 
Scalability is especially noted in the distance technology systems, whereby effective technology is used to remove the mundane tasks. For example, by using an IMS package, an instructor can rely on the technology for grading of tests, reporting of grades, group announcements and chat rooms that address a wide variety of agenda items.

\section{Cost to run the program}

Costs involved in running the NTC Practical Nursing Program involve all costs associated with onsite delivery except for plant operation costs. It is duly noted that to have cost efficiencies, retention of students must be maintained. In turn, maintaining retention requires effective student services. While experienced in online learning, the college still struggles with balancing quality and cost efficiency. Both the financial stature of administrative services providing student support, and learning and teaching must be addressed to conquer the economics of online deliveries.

In its initial online course implementations, in error the college assumed efficiencies would easily be noted in administrative staff needed to disperse information to students and assist in problem solving. At the outset, the course pilots proved that assumption true. However, since the inception of its online degree programs and thus larger enrollments the need for revamping the traditional student services and support processes has emerged. Akin to online learning, online student support and services takes rethinking too. Only when the college has moved these administrative elements into an online function will it truly realize an overall cost efficiency and scalability.

The majority of costs for distance learning and teaching systems reside in faculty. Only with attention granted to direct and indirect factors can institutions truly find an effective workload management tool. At NTC workload is managed through two elements - the number of courses a faculty member teaches and enrollment within the courses. Faculty provide input on enrollment caps, typically promoting an expectation that more students can be handled in a lecture than within a lab or clinical. Both faculty and administration are committed to quality and are well aware that financial efficiencies must be acknowledged too. The bargaining agreement for NTC is completed at the state level, considerate of input from colleges and their faculty. The current statewide contract is almost silent about distance workload delegating the implementation to the colleges themselves. In an effort to operate within an emerging world of distance and technology-based learning and teaching the college administration partners with program faculty to create common understandings of workload guided by very little precedence.

Effective management of faculty time requires consideration of several factors, some obvious and others that are somewhat invisible to the newcomer in distance education. Of obvious concern is the number of students enrolled in distance courses. Much like the on-campus programs this number is affected by the nature of the course, lecture, lab or internship and the program's accreditation guidelines. In addition and less obvious, the faculty time associated to the online program is indirectly affected by numerous factors. Of closest association to the faculty is the individual's collective experience with the learning and teaching process, online teaching, instructional technology and motivation to teach online (desire versus assignment to fulfill a contract obligation). The institution's systems also affect the faculty time. For insurance at NTC, it is recognized that the level of staff development provided to re-skill campus faculty to online teaching makes a difference on how many students the faculty member can handle in an online course. Also affecting the faculty workload are the intuitive level of Instructional Management Software (IMS) and other technologies, the use of IMS and other technologies within the campus programs, the role identified for faculty roles within the student admission and enrollment processes and student preparedness for online learning. 
NTC operates in a 3-year upstart cycle seeking to attain financial efficiency by year three. Without a better method in hand, the college strives to reach an overall teacher to learner ratio of 1:18. This ratio is similar to the targets set for most on-campus programs with some programs targeted at a higher ratio. Typically establishing higher enrollments in lecture courses afford lower enrollments in lab and clinical courses and provide a pathway to attaining the desired overall ratio. While mining for the best workload tools, both college administration and faculty recognize that if the need for course enrollment caps is not recognized in favor of a solely revenue focus, effectiveness is at risk and program ruin will loom on the horizon.

In delivering the distance nursing program, the highest costs are associated with teaching the nursing labs and clinicals. The reason for the high cost is the lower student to faculty ratio. In a didactic class, the ratio can easily be 1:30. However, in the skills and clinical setting, it is reasonable that the ration be approximately 1:8. However, wages are the same for similar credit theory, lab or clinical course. This is a perplexing and complex issue to resolve regarding cost efficiency. NTC has come to realize, for the present moment, that these few lab and clinical courses will be very expensive to the institution, but realize that the didactic classes and other distance course revenues can assist in covering the cost of these high-cost courses. It should be noted that these same lab and clinical courses are expensive to the on-site programs as well because lower student-faculty ratios in labs/clinicals is a phenomena not unique to distance delivery.

Effectiveness and efficiency are realized through understanding the distance delivery system by all members of the college. For example, “...administrators and department chairs must realize the importance of lead time and proper planning for distance course. If instructors are given short notice and limited support, that reality is that, at best, they may be able to reconfigure only two or three classes. Ineffective teaching will be the result, even if the instructor has the best possible intentions" [3].

\section{Costs of Infrastructure}

The basic infrastructure to deliver distance education includes: (a) appropriate basic technologies of servers, wiring, LAN, WAN connections, computers and software; (b) information technology personnel; and (c) software licensing. At NTC, the technology infrastructure was established prior to the advent of distance education. NTC has utilized laptops in the classroom for several years and is recognized as a laptop college. Many programs of the college require students to have a laptop to complete their coursework. This infrastructural groundwork had been installed well before the distance education department existed and certainly helped expedite the implementation of distance courses.

As the number of distance course offering increase, software applications and efficiencies become most notable. Many software companies provide financial incentives directly proportional to the number of licenses purchased. There are other efficiencies that can be noted simply due to increased staff and faculty experience with distance education. We assess, plan, implement, and evaluate and reconfigure delivery based on experience. Distance delivery of nursing education closely parallels telehealth. Chaffee [11] states that, "telehealth is not in its infancy. It's perhaps better described as a technology in its adolescence. And like many adolescents, it has undergone periods of rapid growth and confusion about its identity, and is beginning to demonstrate financial responsibility" [11]. Distance Nursing is also moving in the right fiscal direction as it gains experience.

\section{E. Costs of Marketing}

According to Mezibov "distance education, by its very nature, draws in would-be students" thereby enhancing program enrollments [8]. Mr. Chambers of Cisco Systems has a similar vision, stating that eeducation will be driven by a net-economy which "'can provide faster learning, at lower costs, with more 
accountability, thereby enabling both companies and schools to keep up with changes in the global economy that now occur at Net speed"' [4].

These are both strong statements regarding distance education. NTC has realized both of these claims. Many students may have taken classes earlier in their life and weren't successful, but due to the convenience and new experiences, are willing to give it another try. Also astute students realize that they can progress through courses at their own speed and at a time of day that fits their life. In this vein, the costs of all types are lower for them and the learning can be much quicker.

When considering marketing NTC's distance education programs, it was realized that a marketing plan was needed. It was also realized that a team of people with breadth of experience both in distance education and marketing would be needed to form a viable team. The tasks for this team will be to evaluate the distance programs, set objectives, identify personnel and equipment, analyze target audience, identify market niche, and select appropriate media. According to Porter "Like any other part of distance learning, advertising and promoting programs is crucial. These activities should be given the same consideration as other development aspects of your program. By developing an effective marketing strategy first, then designing individual advertisements, you can achieve the best results for your program" [13].

\section{F. Significance to the Programs and OL in General}

It is imperative to the success of distance education that institutions involved in online delivery of health programs evaluate their progress. Barriers that have been encountered, counter-actions that have been implemented, and the effectiveness of such counter-actions need to be documented. Publication of the trails and errors of distance health education delivery ought to occur regularly. It is only through this sharing of knowledge that learning occurs among faculty, staff, and administrators interested in this field. Institutions should have the opportunity to proactively plan for and avoid common pitfalls that their distance-delivery predecessors have identified. Professionalism, beneficence, integrity, and active research are concepts that should infiltrate the field of distance health education delivery in a qualitative and quantitative manner which is comparable to the field of healthcare practice.

\section{ISSUES FOR FURTHER CONSIDERATION}

\section{A. Cost-effectiveness versus cost-efficiency}

According to Rumble [16] cost effectiveness deals with outputs. These outputs are relevant to the needs and desires of its students. Cost efficiency relates to the cost of achieving the outputs if the costs per unit are lower than that of another institution. A distance education entity can be effective, but not necessarily efficient, meaning that access and quality are high, but so are costs. The reverse can also exist whereby a distance education entity can be very efficient, but if the quality of courses or access is diminished, the endeavor is lacking.

\section{B. Recommendations: Criterion in making distance education cost effective}

There is compelling evidence that distance education can be more cost effective than traditional delivery. The criteria to realize the economies of scale that lead to cost efficiency include (a) enough students to result in an average cost per student lower than that in traditional educational systems, (b) withdraw rate must be kept low, and (c) number of courses cannot grow so large that it moves the average cost per student above that in traditional delivery systems. Significant factors in cost effectiveness are (a) choice of media, (b) market research to ensure that courses attract enough students, and (c) appropriate investment of adequate resources in student services and infrastructure [16].

\section{REFERENCES}

1. Staff. Actionline NEA: Distance ed quality checklist. NEA Higher Education ADVOCATE, 17 (2), 2. December, 1999. 
2. Online, Iowa Public Television at www.iptv.org/FINELINK/resources/full text/13-full2.htm. Online, Worldbank at http://www-itsweb4.worldbank.org/dited/Management/Benefits/cost01.html2.

3. Cyrs, T. College courses in cyberspace. NEA Members in Higher Education, 17 (3), pp. 5-7. January, 2000.

4. Friedman, T. L. Next, it's e-education. AFT On Campus, p. 18. February, 2000.

5. Staff. Great expectations: How the public and parents-White, African American, and Hispanicview higher education. I, p. 1. May 3, 2000.

6. Peterson, C. A. Nursing supply and demand: Is the nursing profession facing a famine? American Journal of Nursing, 99 (7), p. 57-61. July, 1999.

7. Staff. Capitol: Nursing shortage and nurse staffing. Minnesota Nursing Accent, p. 4. March, 2000.

8. Mezibov, D. Distance Learning Is Changing and Challenging Nursing. Education http://www.aacn.nche.edu/Publications/issues/jan2000.htm.

9. Kuhlenschmidt, S. Practical advice for going online. NEA Members in Higher Education, 17 (2), pp. 5-8. December, 1999.

10. Hirsch, E. D. 'You can always look it up' ... or can you? American Educator, p. 4-9. Spring 2000.

11. Chaffee, M. A telehealth odyssey. American Journal of Nursing, 99 (7), 27-32. July, 1999.

12. Moore, M. G., \& Kearsley, G. Distance education, a systems view. USA: Wadsworth.

NEA and Blackboard Inc. study finds 24 measures of quality in internet-based distance learning. Press Release, pp. 1-4, 1996. March 21, 2000.

13. Carr, S. Electronic classroom: 2 professors find that online chats are unpopular. The Chronicle of Higher Education, p. 1. April 7, 2000.

14. Porter, L. R. Creating the virtual classroom, distance learning with the Internet, USA: Wiley, 1997.

15. Carnevale, D. U of Arkansas tests online nursing courses to ease shortage of RN's. The Chronicle of Higher Education, p. 1. January 31, 2000.

16. Rumble, G. The costs and costing of distance/open education. In J. Jenkins, Ed., Commonwealth Co-operation in Open Learning: Background Papers (pp. 255-58, 264-66). London: Commonwealth Secretariat, 1988.

\section{ABOUT THE AUTHORS}

Tracy Wright is Distance Nursing Coordinator at Northwest Technical College.

Address: Northwest Technical College, 905 Grant Avenue SE, Bemidji, MN 56601-4907; telephone:

218-755-4270; email: Tracy.Wright@,mail.ntc.mnscu.edu.

Linda Thompson is Dean of the Northwest Technical College Virtual Campus.

Address: Northwest Technical College, PO Box 309, Perham, MN 56573; telephone: 218-347-6216;

email: Linda.Thompson@mail.ntc.mnscu.edu. 